\title{
A ESCOLA NACIONAL FLORESTAN FERNANDES: ORIGENS HISTÓRICAS E CONCEPÇÕES TEÓRICO-PRÁTICAS
}

\author{
Lalo Watanabe Minto ${ }^{1}$
}

\section{RESUMO}

A existência de uma escola nacional do Movimento dos Trabalhadores Rurais Sem Terra (MST) é anterior à fundação da sede física da Escola Nacional Florestan Fernandes (ENFF), em janeiro de 2005, e está vinculada ao desenvolvimento do MST como um movimento de dimensões nacionais. Nesse artigo apresentamos alguns aspectos históricos da fundação dessa escola, dos seus primórdios nos anos 1980/1990 até o período de consolidação e desenvolvimento em Guararema/SP, resultantes do projeto de pesquisa coletivo intitulado "Concepções teórico-práticas de educação e trabalho no Movimento dos Trabalhadores Rurais Sem Terra (MST)", financiado pelo CNPq e coordenado pelo Grupo de Pesquisa "Organizações e Democracia", da Faculdade de Filosofia e Ciências da Unesp, campus de Marília. Com relação ao objeto em foco, buscou-se apreender em que medida o MST pôs em prática a "pedagogia do movimento" para "ocupar" o nível superior de ensino. As principais conclusões do estudo indicam que a estratégia prioritária do movimento tem sido a de obter espaços e influência no sistema de ensino regular, secundarizando a perspectiva de construir uma escola superior própria, autônoma e voltada exclusivamente aos interesses do MST.

Palavras-chave: Escola Nacional Florestan Fernandes; MST; ensino superior.

\section{FLORESTAN FERNANDES NATIONAL SCHOOL: HISTORICAL ORIGINS AND THEORETICAL-PRACTICAL CONCEPTIONS}

\begin{abstract}
The existence of a national school of the MST (Landless Rural Workers Movement) precedes the foundation, in January 2005, of its physical headquarter, named FlorestanFernandes National School (ENFF), and it is related to its development as a movement of national dimensions. This paper analyses some historical aspects of this school, since its first steps in the 1980s and 1990s until the consolidation and expansion period in Guararema, São Paulo State. We present here part of the results of the collective research project named "Theoretical-practical conceptions of education and work in MST",financed by the National Council of Scientific and Technological Development (CNPq)and coordinated by the group of research "Organizations and Democracy", of the São Paulo State University (Campus of Marília). The purpose of this paper is to comprehend in what measure MST has implemented your pedagogy to occupy the higher education level in Brazil. The main conclusions of this study point out that the priority strategy of MST has been to obtain spaces and to influence the regular system of education and its practices, relegating the perspective of building your own higher education institution, with plain autonomy, to a secondary position.
\end{abstract}

Keywords: FlorestanFernandes National School; MST; Higher education. 


\section{AS ORIGENS DA ESCOLA NACIONAL FLORESTAN FERNANDES (ENFF)}

A despeito da inauguração de sede física da ENFF em Guararema ${ }^{2}$, em janeiro de 2005, pelo Movimento dos Trabalhadores Rurais Sem Terra (MST), é consenso entre estudiosos do tema, que a Escola não "surgiu" naquele momento. (MEDEIROS, 2002; SILVA, 2005; PRINCESWAL, 2007). Os processos de concepção, amadurecimento e construção da sede da escola nacional (EN) acompanham o próprio desenvolvimento do MST. São frutos de sua trajetória de lutas e vivências concretas, em constante transformação. Segundo Princeswal (2007, p. 108), a escola é uma espécie de "síntese histórica" da formação engendrada pelo movimento ao longo desse tempo.

Segundo Medeiros (2002, p. 49),

A história da EN tem sua origem logo nos primeiros anos após a fundação do MST, realizada durante o I Encontro Nacional do Movimento dos Trabalhadores Rurais Sem Terra, em Cascavel, no Paraná, em 1984, com as primeiras articulações desenvolvidas pelos Sem Terra no intuito de materializar alternativas pedagógicas que permitissem atender a forte preocupação que o Movimento tinha para com a formação e qualificação política de seus quadros.

Nesse primeiro momento, portanto, a concepção de uma EN estava vinculada à pretensão de expandir o movimento por todo o território brasileiro e de garantir autonomia aos seus quadros militantes. Assim, a preocupação com essa formação política tornou-se uma tarefa sistemática ainda na década de 1980. Acompanhando Medeiros, Princeswal (2007) entende que as atividades da EN se iniciaram à medida que se articularam algumas demandas concretas do movimento:

A partir da demanda de formação dos seus próprios militantes e dirigentes, o MST passa a desenvolver cursos, em 1987, para a Coordenação Nacional e inicia uma turma de monitores em nível nacional, para militantes jovens. O curso em questão tinha duração de dois anos, objetivando a formação de dirigentes para organizarem o Movimento nos estados, dentro da perspectiva de movimento autônomo, com novas características organizativas e de lutas. Em 1988, é criado o setor de formação, com o objetivo principal de propor atividades de acordo com as demandas regionais, estaduais e nacionais surgidas de acordo com a realidade vivida. (PRINCESWAL, 2007, p. 119).

Tomando por base relatos de lideranças do MST, Medeiros (2002, p. 50) afirma que a partir desse período, as atividades de formação política passaram a ocorrer com maior regularidade. Num primeiro momento, com os cursos oferecidos pela Escola Sindical "Margarida Alves", no Rio Grande do Sul, mantida por forças ligadas ao movimento sindical $^{3}$ e a Comissão Pastoral da Terra. Não demorou, contudo, para que se iniciasse um processo de construção de escolas do MST.

Os primeiros cursos foram organizados na forma de "brigadas", com o objetivo de qualificar os militantes do movimento para desenvolverem trabalhos de base junto aos trabalhadores rurais, ou seja, para multiplicar seu potencial de ação. (MEDEIROS, 2002, p. 50). Experiências como essas foram amadurecendo a consciência de que, à medida que o 
movimento crescia e se tornava mais organizado em nível nacional, teria de enfrentar a construção de um projeto político próprio de formação.

Para Princeswal (2007, p. 119-120), os acontecimentos do ano de 1989 foram cruciais para impulsionara criação da EN. Dois fatores teriam sido fundamentais: a derrocada do bloco soviético e o processo de fragmentação das esquerdas brasileiras, sobretudo, após a derrota nas eleições presidenciais de 1989, quando se ampliou a tendência de isolamento ${ }^{4}$.

Naquele contexto, os setores intelectuais se encaminharam cada vez mais para nichos acadêmicos, isolando-se dos movimentos de base, ao passo que muitos dos setores militantes ligados aos partidos de esquerda acabaram por se afastar, também, da produção teórica e assumir como prioridade a conquista de espaços pela via eleitoral.

Do ponto de vista do MST, o final da década de 1980 também significou "acertar contas" com as estratégias adotadas pelo movimento no período em que as lutas sociais no país estavam em ascensão. As expectativas quanto à possibilidade de obter conquistas por meio dessas estratégias, sobretudo aquelas relativas à reforma agrária, não se efetivaram e foram seguidas de retrocessos políticos: as propostas do MST não foram incorporadas ao I Plano Nacional de Reforma Agrária (1985) e à Constituição de $1988 .^{5}$ Essa revisão de estratégias passava a incluir processos de formação mais sistemáticos, algo que não havia sido priorizado pelo movimento em seus primeiros anos de existência, conforme afirma Rodrigues (2013, p. 150):

[...] na luta levada adiante pelo MST e no seu vínculo com o PT evidenciam-se, simultaneamente: a centralidade das ocupações de terra e os limites da reestruturação agrária propugnada pelo Partido. Este quadro se apresenta na formação política do Movimento que se deteve à preparação da luta imediata, às justificativas para as ocupações, enquanto não apareciam discussões acerca das razões históricas mais profundas, determinantes para as derrotas.

Com Collor de Mello na presidência da República, reafirmou-se uma política de forte repressão aos movimentos sociais. Essa também foi a avaliação que o movimento fez à época, sintetizada por Princeswal (2007, p. 120-121):

Com a repressão imposta pelo governo Collor, [...], o MST volta-se para a consolidação de sua estrutura organizativa, em especial para a produção nos assentamentos como estratégia de se fortificar internamente. Destacase a experiência dos Laboratórios Organizacionais do Campo, onde o MST objetivava "massificar a cooperação" nos assentamentos.

No mesmo sentido apontado por Medeiros e Princeswal, Silva (2005) trata o ano de 1990 como chave para o surgimento da EN, recuperando outros aspectos que ajudam a compreender as opções educacionais do MST:

No final da década de 1980 e do início da década de 1990, com o refluxo da teologia da libertação e do movimento sindical, que começa a sentir os primeiros golpes do projeto neoliberal sobre o mundo do trabalho, surge a necessidade do MST se responsabilizar por sua própria formação, ou seja, ter seus próprios formadores. (SILVA, 2005, p. 134). 
Para a autora, que também se baseia em relatos de lideranças como Ademar Bogo e ElemarCezimbra, o movimento se viu na necessidade de organizar sua luta em bases mais autônomas, sobretudo no que se referia à forma de compreensão da questão (da reforma) agrária no Brasil. Esta autonomia implicava distanciar-se, de certo modo, das organizações e entidades que até então vinham cuidando das questões estratégicas do movimento: o Partido dos Trabalhadores (PT) e setores da Igreja Católica, em especial aqueles ligados à Comissão Pastoral da Terra.

A ideia de que o movimento deveria desenvolver práticas de formação mais autônomas em relação às forças políticas aliadas,bem como em relação à escolarização oferecida pelo sistema de ensino oficial, se consolidou de modo simultâneo ao processo de fragmentação das forças políticas de esquerda no Brasil, e no qual o governo Collor de Mello tentava frear o ímpeto da luta pela reforma agrária no país. Naquele contexto, tratava-se de uma preocupação com uma formação:

[...]ligada aos objetivos estratégicos da organização, como por exemplo, reforçar as mobilizações de massa e a organicidade interna com os setores urbanos, fortalecer as lideranças e o processo de conscientização política. Ou seja, implementar um conjunto de atividades no âmbito da formação e da prática política de forma a esclarecer o papel do MST no desenvolvimento da luta de classes no Brasil. (SILVA, 2005, p. 136).

Essa proposta estratégica, em construção na virada dos anos 1980 para os 1990, pressupunha que a formação da consciência dos trabalhadores ligados ao MST adquiriria maior densidade à medida que suas lutas ultrapassassem o horizonte da "luta pela terra". Desse modo, ainda segundo Silva (2005, p. 136),

A construção de uma estratégia, que inclui a compreensão da conjuntura política vivenciada pelos primeiros anos de neoliberalismo, a compreensão dos enfrentamentos vividos por outros setores sociais, potencializa o sentido político de cada ação realizada.

Para Caldart (2004, p. 248-249), esse é também um período específico na história do MST, marcado pela sua constituição enquanto organização social ${ }^{6}$ e pela necessidade de construir uma identidade própria do sujeito que está em luta permanente no campo. A luta pela terra continuava a ser o foco do movimento, que, porém, não se restringia a ela. A autora afirma que a criação do Setor de Educação (1987) é um "marco" desse período que vai, pelo menos, até julho de 1997 (ano da realização do Encontro Nacional de Educadores e Educadoras da Reforma Agrária - Brasília):

A ênfase deste segundo momento esteve no processo de produção da chamada proposta de educação ou proposta pedagógica do MST, configurando-se como uma ampliação da própria noção de direito: não apenas ter acesso à escola mas também ter o direito de constitui-la como parte de sua identidade: fazer cada escola conquistada uma escola do MST. (CALDART, 2004, p. 249, grifo da autora).

No balanço que o MST fez do ano de 1992, em seu jornal, ficou claro o reconhecimento da necessidade de expandir os projetos de formação permanente (UM ANO..., 1992, p. 03). E foi nesse mesmo período que surgiram experiências embrionárias do que viria a ser a ENFF, como os já mencionados Laboratórios Organizacionais do Campo. 
Medeiros (2002, p. 47) afirma que a criação da EN propriamente dita ocorreu em $1990^{7}$, quando recebeu o nome de Florestan Fernandes ${ }^{8}$. A referência é o surgimento do Centro de Capacitação e Pesquisa, em Caçador/SC, onde era realizado o "Curso Básico de Formação de Militantes". Diz ainda o autor:

Até novembro de 2000, a Escola Nacional vinha realizando suas atividades do Curso Básico de Formação de Militantes no Centro de Formação e Pesquisa do Contestado - CEPATEC, na cidade de Caçador, Santa Catarina, em um prédio adquirido no final dos anos 80 pelo MST, local que anteriormente abrigava um seminário de formação de religiosos católicos. Nas instalações do CEPATEC, sob a coordenação do MST, assim como no CEAGRO de Cantagalo, além da Escola Nacional realizavam-se vários cursos técnicos oferecidos aos trabalhadores rurais sem-terra pelo MST da região sul (Rio Grande do Sul, Santa Catarina e Paraná). (MEDEIROS, 2002, p. 48).

Sobre a desativação do CEPATEC e o impulso pela busca de uma nova sede, o autor afirma que:

Após dez anos de trabalhos pedagógicos desenvolvidos na sede do CEPATEC [...], o MST necessitou vender o prédio, pois não possuía recursos para realizar a reforma necessária à manutenção da estrutura física do Centro. O fato impulsionou a busca de um novo espaço para a realização das atividades da Escola Nacional. Além disso, a mudança de local se justificava principalmente pelas mudanças ocorridas na proposta pedagógica da EN, com a inserção do trabalho como elemento educativo. As antigas instalações não ofereciam possibilidades de realização de atividades agrícolas e de oficinas pedagógicas contidas no novo currículo. Por outro lado, com o início da construção de uma sede própria para a Escola em São Paulo, com previsão de conclusão das obras para 2003, optou-se pela realização de experiências da Escola em outras regiões, como no Paraná, em março de 2001, e no nordeste, em Sergipe, no segundo semestre do mesmo ano, objetivando enriquecer pedagogicamente a nova proposta. [...]. (MEDEIROS, 2002, p. 48-49).

\section{A ESCOLA NACIONAL ANTES DA CONSTRUÇÃO DA SEDE FÍSICA EM GUARAREMA}

Mais profícuo que encontrar "o momento" de criação da ENFF é especificar o contexto no qual a concretização de uma EN - incluindo a construção de sua sede física se tornou estratégica para o movimento. Passos decisivos nessa direção foram dados durante os dois governos FHC, quando as linhas gerais de um projeto neoliberal foi se consolidando no país. O movimento passou a envidar esforços na estratégia de formação de quadros como meio de fortalecer as lutas pela reforma agrária. (PRINCESWAL, 2007, p. 123).

Lucena e Netto $(2010$, p. 213; 216-217) concordam com essa visão, mas entendem que foi nos governos Lula (de 2003 em diante) que se consolidou o processo no qual a criação da ENFF surge como uma "resposta" ao arrefecimento das lutas pela reforma agrária (e das lutas de classes).

A criação do Instituto de Capacitação e Pesquisa da Reforma Agrária (ITERRA), em 1995, foi outro momento decisivo dessa trajetória. Tratava-se de um centro estratégico 
para formação de quadros do MST (políticos e técnicos, com destaque para a formação de professores), sediado em Veranópolis/RS. O primeiro curso superior ligado ao MST nasceu de convênio do ITERRA com a Unijuí/RS ${ }^{9}$, com apoio do INCRA. Trata-se do "Pedagogia da Terra", cuja primeira turma iniciou-se em janeiro de 1998:

Entre os objetivos do curso definidos pelo setor de educação do MST, destacam-se: a formação de quadros para o MST, principalmente ligados aos setores de educação e formação; especialização de educadores(as) para atuarem nas áreas de assentamento e acampamento; encaminhar a construção e implantação da Pedagogia do Movimento e fortalecer a relação do Movimento com a Universidade com a perspectiva de um projeto universitário para a classe trabalhadora. (ITERRA, 2002, p. 08 apud PRINCESWAL, 2007, p. 122).

Dos esforços em construir alternativas para fortalecer as lutas pela reforma agrária, inicialmente concretizados na experiência de parcerias do Setor de Educação, resultariam, doravante, as parcerias entre o Setor de Formação do MST e diversas universidades, tendo como pano de fundo a criação do Programa Nacional de Educação na Reforma Agrária (Pronera) ${ }^{10}$, em abril de 1998.

Santos (2012, p. 633-634) afirma que o Pronera "instituiu possibilidades de ressignificação do conteúdo e da metodologia dos processos de educação formal, por meio dos princípios básicos de participação e da multiplicação", o que viabilizoua presença e a participação ativas do movimento na dinâmica de organização do ensino (conteúdos e metodologias).Antes de mais nada, o programa criou condições para que sujeitos ligados ao MST entrassem "coletivamente" nas instituições de ensino superior (IES).

De acordo com a documentação consultada e as conclusões a que chegaram os estudos sobre a ENFF, referenciados neste trabalho, pode-se dizer que o surgimento de cursos superiores no MST decorreu do processo de ampliação de sua abrangência enquanto movimento. Com essa maior amplitude, a demanda por formação também ganhou escala nacional e o Pronera contribuiu para consolidar as parcerias com as IES:

O trabalho com cursos formais teve um impulso a partir da criação do Pronera, em abril de 1998. Até então, eram poucas turmas e em poucos lugares. Com o novo programa, envolvendo universidades e institutos federais, foi possível alcançar uma escala maior, potencializando a experiência acumulada de formação por alternância e vinculada aos movimentos. O MST chega em 2011 com 1.500 educadores formados nestas turmas específicas e com 50 turmas em andamento, nas diferentes áreas, com aproximadamente 2 mil educandos de ensino médio, técnico e superior. (KOLLING; VARGAS; CALDART, 2012, p. 506, grifo nosso).

Não há dúvida, também, de que a principal demanda era por formação de professores/educadores para as escolas do movimento. A concepção das "frentes de trabalho" do Setor de Educação denota isso: cada uma delas abrange os níveis, etapas e modalidades de ensino, sendo que o nível superior corresponde justamente à frente de "Formação de Formadores" (SILVA, 2005, p. 148-149).

Mas coube ao Setor de Formação ocupar o papel de sujeito central na formulação e gestão dos convênios do MST com as IES, que ganharam maior escala a partir de 1999, no contexto de avanço do projeto neoliberal que caracterizou o governo $\mathrm{FHC}$ e da submissão 
cada vez maior das questões da reforma agrária àquele projeto. E foi com o curso "Realidade Brasileira" que se estabeleceu uma espécie de padrão - em termos de forma e conteúdo - dos convênios entre aquele setor e as IES (BEZERRA; RODRIGUES; PIZZETA, 2007, p. 09-10), tendo ocorrido na Unicamp, em 1999, sua primeira edição ${ }^{11}$.

Outro marco dos convênios se deu com a Universidade Federal de Juiz de Fora (UFJF) (1999), por ocasião da Marcha Nacional do MST pela cidade. No primeiro semestre de 2003, novos convênios foram estabelecidos com as universidades federais de Uberlândia, da Paraíba e do Maranhão, com a Universidade de Chapecó e a Universidade Católica de Goiás. (BEZERRA; RODRIGUES; PIZZETA, 2007, p. 08-10). Já o primeiro curso de pós-graduação, na modalidade Especialização, foi elaborado, em 2003, também na UFJF, intitulado "Especialização em Estudos Latino-Americanos".

\section{O POLÍTICO E O PEDAGÓGICO EM CONSTRUÇÃO NA EN}

A necessidade de construir uma sede física para a ENse delineou, portanto, num contexto de arrefecimento das lutas pela terra e do avanço das políticas neoliberais no país. Nesse período, o debate sobre as finalidades do projeto educativo da EN ganhou destaque. Em maio de 1998, o MST lançou o Caderno de Formação n 29, intitulado "Campanha de construção da Escola Nacional do MST". Na sua apresentação esclareceu que:

O símbolo da luta pela escolarização e o estudo será nossa Escola Nacional. Ela será fruto do suor de todos os que carregam essa bandeira. (MST, 1998, p. 05, grifo nosso).

O MST tem se alinhado, há anos, aos setores da sociedade brasileira que adotam como bandeira de luta a defesa da educação pública (estatal), gratuita e de qualidade. ${ }^{12}$ Nos termos do "Manifesto das educadoras e dos educadores da reforma agrária ao povo brasileiro", documento produzido no $1^{\circ}$ Encontro Nacional de Educadoras e Educadores da Reforma Agrária - Brasília, 1997, essa mensagem ficou explícita: "Lutamos por justiça social! Na educação isto significa garantir escola pública, gratuita e de qualidade para todos, desde a Educação Infantil até a Universidade" (MST apud CALDART, 2004, p.428). Para o MST, portanto, a importância da escola regular, em todos os níveis e modalidades, não é uma questão secundária, como também afirmam Dal Ri e Vieitez (2008, p. 184): “A primazia educativa atribuída ao Movimento como educador não significa a desvalorização da escola. [...] o MST não apenas reconhece como tem clareza da necessidade e da função da escola".

Um dos princípios mais caros e repetidos pelos quadros do MST, bem como por estudiosos de temas ligados à chamada de "pedagogia do MST" ou "pedagogia do movimento", é o de que a educação e a escola são fundamentais, mas devem ser consideradas "para além de sua condição" na sociedade capitalista. Ou seja, reconhece-se a importância da escola formal e propugna-se sua "ocupação" (CALDART, 2004, passim) ${ }^{13}$. Esta ocupação, porém, não se resume a apropriar-se dos conteúdos da escola e dos benefícios que trariam aos indivíduos formados por ela: enfatiza-se, acima de tudo, o caráter educativo/formador da luta pela escola, elemento crucial na preparação dos quadros do movimento para enfrentar os desafios de transformar a sociedade na qual vivem.

Para Kolling, Vargas e Caldart (2012), o acúmulo de experiências e o diálogo permanente com as diferentes teorias sociais e pedagógicas é que permitiram a construção da "pedagogia do movimento". E se um de seus pilares é a forma distinta de conceber as 
finalidades da escola e seus métodos pedagógicos, também se inclui aí a formação superior. E é nesse sentido que se entende que, a partir da criação do Pronera em 1998, o MST vem "ocupando" também as IES:

A dimensão específica da ocupação da universidade, que iniciou com os cursos de educação e aos poucos foi se estendendo para outras áreas, tem um significado histórico importante na formação de um intelectual coletivo de classe, nesse caso orgânico ao trabalho nas áreas de Reforma Agrária: camponeses trabalhando com camponeses. E a combinação entre escolarização, formação político-ideológica e formação técnica, inaugurada pelos cursos formais das áreas da educação e da produção, foi, aos poucos, se afirmando como uma marca do trabalho de educação do MST. (KOLLING; VARGAS; CALDART, 2012, p. 506).

Por essas razões, Lucena e Netto (2007, p. 220) adotam a leitura feita por Roseli Caldart para afirmar que "não diferente das demais escolas do Movimento", a ENFF se caracteriza como uma "escola do campo". Ou seja, uma escola vinculada ao movimento social de luta pela terra e pela reforma agrária, com participação da comunidade na gestão e tendo na "pedagogia do Movimento" sua orientação geral.

No caso do ensino superior, portanto, o MST não tem a pretensão de substituir aquilo que considera dever do Estado: a oferta regular daquele ensino para todos. O modo como a ENFF vem se organizando não se dissocia daquela perspectiva inicial que mobilizou o MST para o projeto de construção da sede física da escola. Sobre isso, Princeswal (2007, p. 110) afirma que, ao se tornar cada vez mais um movimento de massas, o MST se viu diante da necessidade de ter, também, uma "organização de massa". Desenvolvimento este que foi decisivo para encaminhar a construção da sede física da ENFF, haja vista que a própria construção poderia ser usada como meio para multiplicar as lideranças do movimento:

O acúmulo de experiência organizativa fez com que o MST, nos últimos anos, reestruturasse o seu funcionamento a partir das chamadas brigadas e não mais em grandes regionais, o que "permite maior participação dos homens e mulheres e facilita a multiplicação de lideranças" (MST, 2005e apud PRINCESWAL, 2007, p. 111).

$\mathrm{Na}$ relação entre essa reestruturação organizativa do movimento e a construção da ENFF, destaca-se o caráter "formativo" dos acampamentos e assentamentos. Donde o mesmo autor pôde reforçar que:

[...] além de tentar proporcionar maior participação de todos na sua base social e descentralizar os espaços de decisões, o MST pretende com o funcionamento das brigadas aumentar o número de lideranças, o que é vital para a organização. Essas mesmas lideranças que organizam o trabalho desde a base, passando pelos setores e direções estaduais, que

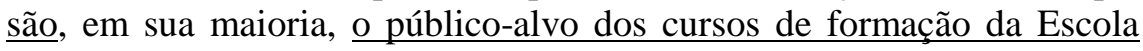
Nacional Florestan Fernandes. (PRINCESWAL, 2007, p. 113, grifos nossos).

\section{O POLÍtico E O PEDAGÓgICO NA CONSTRUÇÃO DA EN}

Para compreender o significado político-pedagógico almejado pelo MST no caso da ENFF, antes de mais nada, é preciso observar o seu processo de construção. Não por outra 
razão, os estudos que trataram da escola valorizam bastante o modo de organização diferenciado do trabalho durante aquela etapa. São ressaltadas, principalmente, as consequências do trabalho voluntário sobre o conjunto de trabalhadores/as envolvido. Alguns desses aspectos referem-se: ao caráter formativo do trabalho (como princípio da formação da consciência política); ao voluntarismo como meio de superar a lógica de exploração e alienação do trabalho; à necessidade de unir estudo e trabalho. Segundo esses estudos, todos esses elementos puderam ser vivenciados pelos voluntários na construção da ENFF.

Para João Pedro Stédile, o fato de a ENFF ter sido construída - e ainda seja mantida - com base no voluntarismo, na solidariedade e no trabalho diário e sistemático dos militantes e apoiadores do movimento, caracteriza o que ele denominou de "afetividade socialista”. (STÉDILE, 2011, p. 71).

Ana Pizzeta (2007a, p. 30), por sua vez, afirma que a construção da ENFF criou possibilidades objetivas para um amadurecimento político dos/as trabalhadores/as voluntários nela envolvidos e, também, para formar uma "nova consciência" baseada no princípio de união entre estudo e trabalho. Das mais simples tarefas no canteiro de obras às decisões coletivas, fizeram com que essa experiência se "transformasse em um espaço de criação de novas relações sociais e humanas entre as trabalhadoras e os trabalhadores voluntários", que foram "construindo a si mesmo como cidadãos".

Ainda para a autora, a experiência da ENFF extrapolou - e extrapola - os limites do MST, atingindo até mesmo uma perspectiva internacionalista (intercâmbio de experiências formativas e de organização com movimentos de vários outros países). O exercício da solidariedade, do companheirismo, da responsabilidade, entre outras premissas do trabalho voluntário nos moldes em que foi organizado, deu origem a uma "nova pedagogia do trabalho, coletivo e voluntário, recheada de solidariedade e relações humanas" (PIZZETA, 2007a, p. 35). Enfim, "o trabalho voluntário, a solidariedade e a formação, praticados no âmbito da ENFF, são, em um espaço micro, ensaios daquilo que os homens livres são capazes de edificar para eles próprios e para a sociedade como um todo" (PIZZETA, 2007a, p. 46).

\section{A ENFF SEGUNDO SEU PROJETO DE FORMAÇÃO}

Vimos que a construção da sede em Guararema orientou-se pela necessidade de encontrar caminhos para que o MST continuasse a "ocupar" o ensino superior no país; e que, além disso, ela própria adquiriu caráter formativo na perspectiva da "pedagogia do movimento". Mas é lícito perguntar: do ponto de vista de seu funcionamento efetivo, uma vez terminada essa etapa de sua construção, qual é a natureza dessa escola?

O que se busca com a questão acimanão é uma caracterização formal da $\mathrm{ENFF}^{14}$, mas suscitar reflexão sobre o papel formativo que ela vem cumprindo; sobre o projeto político-pedagógico que tem sido posto em prática.

Princeswal (2007, p. 135-136) cita Geraldo Gasparin e destaca que foi num Seminário realizado antes mesmo da inauguração oficial da escola, que as linhas gerais do papel a ser desempenhado pela ENFF foram "clareadas":

Evidentemente que no início se tinha essa dimensão: vamos fazer uma escola para os Sem Terra, vamos fazer uma universidade para os Sem Terra! Mas o seminário deu um outro caráter para a Escola e as intervenções que foram feitas naquele seminário apontavam neste 
sentido: olha, temos que ter um espaço onde efetivamente a gente consiga avançar do ponto de vista teórico, político, organizativo no conjunto da classe trabalhadora! Não é uma estrutura física que se projeta ser uma universidade, poderá sê-lo! Mas, ela tem a preocupação fundamental de preparar os nossos militantes, os nossos dirigentes da classe trabalhadora que pense um projeto de transformação de país e de sociedade. (GERALDO GASPARIN, 2007 apud PRINCESWAL, 2007, p. 136, grifo nosso).

Noutra ocasião, o mesmo Gasparin apresentou a questão em termos distintos:

Havia o debate: a Escola Nacional seria a universidade dos trabalhadores Sem Terra, da classe trabalhadora? Mas entendemos que a educação é dever do Estado, uma educação pública gratuita e de qualidade, como sempre disse Florestan Fernandes. Portanto, a ENFF se reserva em complementar temas e aprofundar debates que, geralmente, nas universidades não ocorrem e que para nós são fundamentais. Principalmente na área da filosofia, sociologia, economia política, agrária. E não buscamos a diplomação por diplomação. Consideramos que a universidade tem acúmulo na metodologia, na pesquisa, mas não deixamos de aprofundar e adequar o conteúdo à nossa realidade. (GASPARIN, 2009, p. 03).

Concordando, de modo geral, que o papel da escola é o de articular asatividades e tarefas ligadas à formação política dos quadros do movimento, mas sem perder de vista a importância de qualificar tecnicamente os trabalhadores, Princeswal tira conclusões sobre o sentido amplo no qual o ensino superior é entendido no âmbito da ENFF:

Quando o Movimento se refere aos cursos superiores, não considera apenas aqueles de graduação, mas os cursos em nível mais elevado de formação política, para dirigentes e formadores do MST e dos demais movimentos sociais que já passaram por outros processos de formação. (PRINCESWAL, 2007, p. 136).

A intenção do MST de criar a sua universidade ${ }^{15}$, em muitos sentidos, deu lugar à construção de um instrumento para ocupar o ensino regular, mediante financiamento estatal do Pronera. Quando se iniciou a construção da sede física da ENFF, o formato dos convênios entre MST e universidade já estava delineado segundo um certo padrão.

Outros estudos deverão ser feitos para elucidar melhor esse aspecto, mas é bastante plausível que essa relação não só tenha se viabilizado inicialmente, como também se expandido, no interior das IES, por conta dos recursos disponibilizados pelo programa. A consolidação da ENFF e a existência do Pronera são processos convergentes, sobretudo a partir dos governos Lula (2003-2010), quando o programa passou a integrar o orçamento da União(SANTOS, 2012, p. 633) e ganhou status de política de Estado. Afinal, num contexto de reforma e de crescente estímulo ao "produtivismo acadêmico", que isola as universidades de qualquer "função social" mais significativa, teriam elas aceitado tais parcerias não fosse pelo dinheiro público injetado pelo Programa?

Na visão de Pizzeta (2007, p. 244-246), os objetivos formativos perseguidos pela ENFF e, de modo geral, do que entende ser a formação política necessária aos desafios que se abrem para os movimentos sociais revolucionários (como considera o MST), são muito avançados. Trata-se de uma formação com base teórica sólida e crítica, com vistas a 
preparar militantes revolucionários aptos a compreenderem a dinâmica dos processos históricos (global, regional e brasileiro) que caracterizam o modo de produção capitalista atual, bem como construir instrumentos de intervenção consciente sobre a realidade. Ou seja, potencializar sua capacidade teórica e prática de fazer com que os conflitos de classes avancem no sentido da superação do capitalismo.O autor completa:

A ENFF [...] surge com o propósito de pensar, programar, planejar, organizar e desenvolver a formação política e ideológica dos militantes e dirigentes do conjunto do MST. Ela passa a ser um (não o) espaço de articulação das inúmeras iniciativas e experiências que estão em curso nos estados e articuladas pelos diferentes setores de atividades no MST, no sentido de buscar uma maior unidade e qualificar essa práxis. (PIZZETA, 2007, p. 246).

Importante mencionar que esse papel de articulaçãotambém envolve articulações no plano internacional, não restritas aos objetivos do MST:

A ENFF é um conjunto de ações políticas e formativas-pedagógicas, organizadas e realizadas pelo Movimento, independentemente do local e momento de sua realização. Essas atividades também podem ser em parceria, convênios com outros centros de educação e formação, institutos de ensino, tanto do Brasil, como localizados em outros países. (PIZZETA, 2007, p. 247).

Do ponto de vista das atribuições institucionais da ENFF, Leher (2005) também entende que o papel da escola é antes "complementar" que de "substituição" ao sistema de ensino superior vigente no país. Ademais, as universidades públicas e seus nichos mais críticos podem (e devem) contribuir com a produção de saberes na ENFF:

[...] os setores engajados na criação do pensamento original nas universidades devem assumir a ENFF como uma tarefa pública e de mão dupla, mais claramente, os saberes produzidos nas universidades são fundamentais para converter a Escola em um centro pulsante de produção de conhecimento - os diversos convênios do MST com universidades públicas atestam isso, mas, ao mesmo tempo, os diálogos na Escola criarão saberes e uma episteme que podem fortalecer e dar sentido ao fazer acadêmico renovado nas universidades públicas. (LEHER, 2005, p. 04).

O caráter formal da ENFF, portanto, possui pelo menos dois vetores fundamentais: sua relação direta com o surgimento e institucionalização do Pronera, base objetiva dos convênios e parcerias que o MST faz com IES, reconhecidas pelo MEC; e o acesso à formação de nível superior com certificação garantida (diplomas e prerrogativas das diferentes categorias profissionais).

\section{ORGANIZAÇÃO E FUNCIONAMENTO DA ENFF}

No funcionamento efetivo da ENFF, também estão presentes aqueles elementos valorizados pelo MST e característicos da "sua" pedagogia. Assim são planejados, organizados e executados os cursos, eventos e outras atividades da escola. Os princípios de auto-organização, direção coletiva, gestão democrática, disciplina e outros, também se aplicam aos cursos realizados em parcerias com outras instituições, como as universidades, 
sendo que "é possível haver adaptações de acordo com a realidade local". (PRINCESWAL, 2007, p. 142).

Sobre esse modo de organização/funcionamento, a resposta de um de seus coordenadores, Adelar Pizzeta, oferece síntese esclarecedora:

[RST: Qual a diferença, na prática, da ENFF com relação a uma escola/universidade tradicional?]

Procuramos na Escola, trabalhar com sujeitos, não com indivíduos. Aqui, todos e todas possuem nome, não números. Possuem aptidões, que devem se transformar em compromissos coletivos, na construção do ambiente educativo da vida cotidiana. Esses sujeitos assumem tarefas de manutenção da escola, limpeza, lavação de louças, trabalho na produção, enfim, uma série de ações com as quais os estudantes das universidades não precisam se preocupar. Aqui, o funcionamento da Escola exige a contribuição dos educandos, pois não existem funcionários para deixar tudo limpo e organizado. Logo, a coletividade é responsável pela sua existência, manutenção e continuidade. Portanto, o trabalho é uma dimensão pedagógica, educativa fundamental na ENFF.

Outro diferencial está relacionado à forma organizativa dos educandos. Todos participam dos Núcleos de Base, com divisão de tarefas e responsabilidades internamente, como forma de garantir o cumprimento das atividades práticas, de estudo, cultura. Enfim, essa organicidade é fundamental e também passa a ser uma dimensão pedagógica da ENFF. [...]. (PIZZETA, 2010, grifos nossos).

Busca-se, com isso, não separar a condição de educando daquela de responsável pelo funcionamento e manutenção da escola; não dissociar os compromissos com o estudo e com as tarefas cotidianas, ainda que hajaum coletivo de membros permanentes ${ }^{16}$ na ENFF. Todos os que frequentam cursos se encarregam da limpeza, dos cuidados com a horta e outros trabalhos de manutenção. (ASSOCIAÇÃO..., [s.d.]).

Essa lógica não se estende, entretanto, à criação de cursos e seu acompanhamento. Segundo Princeswal (2007, p. 142), estas são tarefas específicas do Departamento de Cursos Formais, um dos três que estão ligados à Direção Política de Formação, acima da qual se situa apenas a Coordenação Geral. Embora aquele departamento centralize as decisões, não é prerrogativa exclusiva dele a proposição de novos cursos, que também podem partir dos setores regionais do movimento.

"[Além] da iniciativa interna do Movimento há casos que ocorrem em sentido contrário, quando são da própria universidade e/ou professores que procuram o MST, interessados em firmar algum convênio", afirma ainda Princeswal (2007, p. 144). Isso não significa que o MST sempre aceite fazer as parcerias, o que só ocorre quando as instituições oferecem propostas curriculares de interesse do movimento (GASPARIN apud PRINCESWAL, 2007, p. 145). De modo geral, observa-se que:

[...] a relação entre as instituições de ensino superior e a ENFF não é um processo linear, muito menos homogêneo em todas as experiências onde são realizados os cursos, visto que é marcada por inúmeras contradições, avanços e recuos. (PRINCESWAL, 2007, p. 145). ${ }^{17}$ 
Quanto à formação de graduação, as parcerias da ENFF com instituições públicas e privadas têm envolvido cursos em áreas como pedagogia (incluindo a licenciatura em educação do campo), geografia, serviço social, direito, veterinária, ciências agrárias, ciências sociais e história. Além disso, há projetos de extensão, cursos de curta duração e, mais recentemente, têm crescido os cursos de especialização (pós-graduação lato sensu). Atualmente, há dois cursos de pós-graduação stricto sensu em funcionamento: o Mestrado em Desenvolvimento Territorial na América Latina e Caribe, em parceria com a Universidade Estadual Paulista "Júlio de Mesquita Filho" e a Cátedra UNESCO de Educação do Campo. (ASSOCIAÇÃO..., [s.d.]); e o Mestrado Profissional em Trabalho Saúde, Ambiente e Movimentos Sociais, com a Escola Nacional de Saúde Pública (ENSPFiocruz). (MST, 2014).

\section{CONSIDERAÇÕES}

O que caracteriza a ENFF não é sua identidade enquanto escola de nível superior. ${ }^{18}$ Ela é um centro que articula $^{19}$ projetos de formação de outras instituições educativas, estas, sim, reconhecidas formalmente. E mais: é por meio da escola que o movimento tenta introduzir novas identidades nesses cursos de formação superior em parcerias com instituições já consolidadas.

Tentamos explicitar que a preocupação do MST com o ensino superior vem sendo alimentada há anos e antecede a existência da ENFF. Esta preocupaçãonão está desvinculada das demais etapas do ensino, como o demonstra a recorrente menção ao problema da formação de professores, entendida pelo movimento como chave para a escolarização elementar de suas bases. (MST, 2010, p. 23-24).

Pelo fato de ser ela própria parte de um processo de construção permanente, característico das ações do MST no campo educacional, a apreensão do real sentido da ENFFé também algo que está sendo construído pelo movimento. O mesmo vale para sua proposta político-pedagógica.Em 2007, o estudo de Princeswal afirmava que ainda era cedo para se falar numa proposta consolidada, entretanto, percebia-se:

[...] a intenção de se criar um currículo mínimo ao qual serão submetidos todos aqueles que passem por qualquer um dos cursos propostos pela ENFF, a fim de oferecer uma mesma base formativa para os militantes, reforçando a identidade coletiva do MST. [...]. Além disso, há o interesse de futuramente contar com um corpo docente permanente [...]. (PRINCESWAL, 2007, p. 171, grifo nosso).

Essa apreensão sugere que a tendência observada era a de consolidação de uma identidade mais autônoma, o que o próprio autor antecipava ser difícil por conta da necessidade de ter que dialogar - e negociar - cada curso com diferentes instituições e em contextos que se modificavam rapidamente.

Como já apontado, disso tudo sobressaicerta controvérsia sobre ocaráter formal da ENFF:se é escola superior, universidade popular, ou, ainda, escola de formação política que tende a seafastar de uma institucionalidade própria, como sugerira Adelar Pizzeta, em trecho citadona página 14.Em matéria assinada por Santos (2005)na Revista Sem Terra, quando da inauguração em Guararema, o mesmo Pizzetaapresentava outro horizonte para a escola: 
O maior desafio dessa nova empreitada do MST é transformar o complexo de ensino na primeira Universidade Popular do Brasil. "Aㅗ médio prazo, pretende-se constituir o Instituto de Ensino Superior Florestan Fernandes, reconhecido pelo MEC, como possibilidade de abrir cursos e graduar militantes e dirigentes dos movimentos sociais. (SANTOS, 2005, p. 33, grifo nosso).

A "Escola", como os dirigentes do MST costumam denominá-la, vem exercendo um papel de articulação entre o sistema formal de ensino superior e as necessidades e demandas do movimento em termos de formação técnica e política. Vem promovendo a "ocupação" de parte do ensino superior regular e, ao mesmo tempo,realiza cursos de formação política para militantes, dirigentes e outros membros de movimentos sociais, como fazia desde os tempos da Escola Sindical "Margarida Alves".Tenta-se evitar, assim, a dicotomia formação técnica-formação política.

Uma leitura mais "orgânica" ao movimento aponta que a "ocupação" também vem produzindo outros resultados. Neste sentido, aposta-se que a "educação do campo" venha a se converter em nova área de estudos e pesquisas nessas instituições. Uma espécie de combinação entre escolarização, formação política-ideológica e formação técnica, que, aos poucos, pudesse formar um "intelectual coletivo de classe", orgânico ao trabalho nas áreas da reforma agrária. (KOLLING; VARGAS; CALDART, 2012, p. 506). Sobre isso, Santos (2012, p. 634) afirma, ainda, que:

O Pronera produziu, no âmbito do debate acadêmico, o diálogo com uma nova perspectiva de produção do conhecimento e de pesquisa; legitimou o conflito no ambiente da universidade, ao reconhecer os camponeses como sujeitos de direitos [...]; e estabeleceu um rompimento conceitual, ao reconhecê-los como portadores de conhecimento, e não apenas como objeto de pesquisa. (SANTOS, 2012, p. 636).

Como se poderia imaginar, construiu-se no movimento um discurso positivo e favorável à continuidade dos convênios/parcerias. Estudos sobre as suas especificidades, bem como sobre as formas de recepção e abrigo desses cursos nas IES, poderão mostrar efetivamente como tem sido essa relação. Em suma, se é possível garantir avanços no sentido da superação da dicotomia já apontada (formação técnica - formação política) em instituições consolidadas, com conteúdos e professores formados e, de certo modo, já "aculturados" nesses ambientes acadêmicos.

De todo modo, tais discursos não parecem conformados com a situação alcançada, pois apontam para uma luta ainda em curso. Quanto ao alcance obtido pelos convênios da ENFF/MST com universidades e outras IES, promovendo acesso a este nível de ensino para os integrantes do movimento, trata-se de algo relativamente bem sucedido. Contudo, é pertinente investigar as condições nas quais isso ocorre e se os cursos garantem o mesmo padrão de qualidade e de formação aos estudantes.A presente pesquisa é insuficiente para avaliar esse conjunto de elementos, limitando-se apenas a menciona-los com a perspectiva de estimular estudos futuros. 


\section{REFERÊNCIAS:}

ASSOCIAÇÃO DOS AMIGOS DA ENFF.Instalações. Disponível em:

<http://amigosenff.org.br/pt-BR/a-escola/instalacoes>. [s.d.]. Acesso em: 07 jul. 2014.

BEZERRA, C.; RODRIGUES, M.; PIZETTA, A.A parceria UFJF/Escola Nacional Florestan Fernandes - MST: a experiência e a produção de conhecimentos do curso de especialização em estudos latino americanos. Libertas, Juiz de Fora, MG, ed. especial, fev. 2007, p. 01-23.

BIONDI, A.Escola Florestan Fernandes, marco na história do MST. Revista Adusp, São Paulo, jan. 2006. p. 15-22.

CALDART, R. S.Pedagogia do Movimento Sem Terra. $3^{\text {a }}$ ed. São Paulo: Expressão Popular, 2004.

DAL RI, N.; VIEITEZ, C.Educação democrática e trabalho associado no movimento dos trabalhadores rurais sem terra e nas fábricas de autogestão. São Paulo: Ícone: Fapesp, 2008.

FERNANDES, B. M.Formação e territorialização do MST no Brasil. In: CARTER, M. (org.). Combatendo a desigualdade social: o MST e a reforma agrária no Brasil. São Paulo: Editora Unesp, 2010.p. 161-197.

FILGUEIRAS, O. Entrevista com Luis Carlos Guedes Pinto. Revista Sem Terra. São Paulo: MST, n.08, jul./ago./set. 1999, p. 20-25.

GASPARIN, G.Contra a ideia da força, a força das ideias. Jornal Sem Terra, n. 295, ago. 2009. Disponível em: 〈http://www.mst.org.br/jornal/295/entrevista>. Acesso em: 20 fev. 2013.

KOLLING, E.; VARGAS, M.; CALDART, R.MST e educação. In: CALDART, R. et al. (org.). Dicionário da educação do campo. Rio de Janeiro: Escola Politécnica de Saúde Joaquim Venâncio; São Paulo: Expressão Popular, 2012. p.502-509.

LEHER, R.Escola Nacional Florestan Fernandes: um grande acontecimento para a educação e para as lutas sociais no Brasil. Outro Brasil - Laboratório de Políticas Públicas (LPP), UERJ, 15 fev. 2005. Disponível em: <www.outrobrasil.net>. Acesso em: 19 fev. 2013.

LUCENA, C.; BORGES NETTO, M.Escola Nacional Florestan Fernandes e a formação dos trabalhadores rurais sem terra: as atribuições do movimento frente à sua base. Revista HISTEBR On-line. Campinas, n. 39, p. 211-224, set. 2010.

MEDEIROS, E. C. de. A dimensão educativa da mística sem terra: a experiência da Escola Nacional "Florestan Fernandes". Dissertação (Mestrado). Florianópolis, SC: UFSC, Centro de Ciências da Educação. 2002.

MST. Campanha de construção da Escola Nacional do MST. Caderno de Formação n. 29, São Paulo: MST, 1998. 
Lutas e conquistas. Reforma agrária: por justiça social e soberania popular. $2^{\mathrm{a}}$ ed. São Paulo: Secretaria Nacional do MST, jan. 2010.

Manifesto das educadoras e dos educadores da reforma agrária ao povo brasileiro. In: CALDART, R.Pedagogia do Movimento Sem Terra. $3^{\text {a }}$ ed. São Paulo: Expressão Popular, 2004. [anexo]. p. 427-429.

Movimentos sociais realizam cursos de especialização e mestrado no

RJ.22/05/2014. Disponível em: <http://www.mst.org.br/node/16142>. Acesso em: 07 jul. 2014.

Terra Nossa - Boletim informativo do Movimento dos Trabalhadores Rurais Sem Terra - São Paulo. Ano II, n. 08, jan./fev. 1994. Disponível em: <http://docvirt.com/docreader.net/DocReader.aspx?bib=G:ITrbs_NIShad_CEDEM_BiblL T\CDEM_BiblLT.DocPro>. Acesso em: 30 maio 2014.

NETTO, J. P.Em busca da contemporaneidade perdida: a esquerda brasileira pós-64. In: MOTA, C. (org.). Viagem incompleta. A experiência brasileira (1500-2000): a grande transação. $2^{a}$ ed. São Paulo, Editora Senac São Paulo, 2000. p. 219-45.

PIZETTA, A. J. A formação política no MST: um processo em construção. OSALAno VIII, n. 22, set. 2007. Buenos Aires: CLACSO. Disponível em:

<http://bibliotecavirtual.clacso.org.ar/ar/libros/osal/osal22/EMS22Pizetta.pdf >. Acesso em: 20 fev. 2013.

Apresentação dos cadernos da ENFF. In: ENFF. Cadernos de estudos ENFF 2. Literatura e formação da consciência. Guararema, SP: ENFF, 2011. p. 07-13.

Na ENFF o conhecimento constrói consciências.Revista Sem Terra, São Paulo, 30 dez. 2010. [Entrevista]. Disponível em: <http://www.mst.org.br/Na-ENFF-oconhecimento-constroi-consciencias>. Acesso em: 03 jul. 2014.

PIZETTA, A. M. J. A construção da Escola Nacional Florestan Fernandes: um processo de formação efetivo e emancipatório. Libertas, Juiz de Fora, MG, ed. especial, p. 24-47, fev. 2007a.

PRINCESWAL, M.MST e a proposta de formação humana da Escola Nacional Florestan Fernandes: uma síntese histórica. Dissertação (Mestrado). Rio de Janeiro: UERJ, Faculdade de Educação. 2007.

RODRIGUES, F. de C.MST: formação política e reforma agrária nos anos de 1980. Campinas, SP: [s.n.]. Tese (Doutorado). Unicamp, Faculdade de Educação, 2013.

SANTOS, C. A. dos. Programa Nacional de Educação na Reforma Agrária (PRONERA). In: CALDART, R. et al. (org.). Dicionário da educação do campo. Rio de Janeiro: Escola Politécnica de Saúde J. Venâncio; São Paulo: Expressão Popular, 2012. p.631-639.

SANTOS, S. A. dos. MST inaugura Escola Nacional Florestan Fernandes. Revista Sem Terra, n. 28, jan./fev. 2005.p. 30-35. 
SILVA, R. M. L. da.A Dialética do Trabalho no MST: a construção da Escola Nacional Florestan Fernandes.Tese (Doutorado). Niterói: UFF, 2005.

STÉDILE, J. P.Saudação em nome da direção nacional do MST. In: ENFF. Cadernos de estudos ENFF - 2. Literatura e formação da consciência. Guararema, SP: ENFF, 2011.p. 69-72.

STÉDILE, J.; HILARIO, E.; FUSER, I. Escola Nacional Florestan Fernandes: seja um associado. Brasil de Fato. 19/07/2013. Disponível em:

<http://www.brasildefato.com.br/node/13666>. Acesso em: 07 jul. 2014.

TAFFAREL, C.; MOLINA, M.Política educacional e educação do campo. In:

CALDART, R. et al. (org.). Dicionário da educação do campo. Rio de Janeiro: Escola Politécnica de Saúde J. Venâncio; São Paulo: Expressão Popular, 2012.p. 571-578.

UM ANO de muita luta. Jornal Sem Terra. São Paulo, n. 121, nov. 1992, p. 03.

\footnotetext{
${ }^{1}$ Professor do Departamento de Filosofia e História da Educação, da Faculdade de Educação da Unicamp. Contato: lalo@unicamp.br.

${ }^{2}$ Município paulista com população de aproximadamente 27 mil habitantes, situado a $60 \mathrm{~km}$ da capital.

${ }^{3}$ Rodrigues (2013, p. 105) menciona, ainda, a Escola Sindical Eloi Ferreira da Silva, nos estados de Minas Gerais, Espírito Santo e Bahia.

${ }^{4}$ Sobre esse processo, ver Netto (2000, p. 239-40).

${ }^{5}$ Sobre o MST e as lutas pela reforma agrária na década de 1980, ver Rodrigues (2013).

${ }^{6}$ O próprio movimento assim se reconhece, ao menos desde 1998, quando foi publicado o Caderno de Formação n. 29, intitulado "Campanha nacional de construção da Escola Nacional do MST" (MST, 1998, p. 07). Fernandes (2010, p. 162-163; 170-173), embora adote periodização distinta à de Caldart, refere-se a esse período (1985-1989) como de “consolidação do MST”.
}

${ }^{7}$ No breve histórico feito pelo MST de São Paulo, no boletim "Terra Nossa", quando da comemoração dos dez anos do movimento, confirma-se a criação da EN no ano de 1990. (MST, 1994, p. 07).

${ }^{8}$ Em depoimento de Maria Gorete, uma das coordenadoras da ENFF à época da inauguração, coletado pelo jornalista Antonio Biondi, indica-se que o nome Florestan Fernandes foi escolhido somente em 1997, pela Coordenação Nacional do MST. (cf. BIONDI, 2006, p. 19).

${ }^{9}$ A Universidade Regional do Noroeste do Estado do Rio Grande do Sul é uma fundação filantrópica.

${ }^{10}$ Segundo Santos (2012, p. 631), o Pronera "é uma política pública do governo federal, específica para a educação formal de jovens e adultos assentados da Reforma Agrária e do crédito fundiário e para a formação de educadores que trabalham nas escolas dos assentamentos ou do seu entorno e atendam a população assentada". Sobre o contexto no qual se instituiu o Pronera, ver: Taffarel e Molina (2012); Kolling, Vargas e Caldart (2012).

${ }^{11} \mathrm{O}$ "Realidade Brasileira" foi realizado como extensão universitária, reunindo cerca de 1200 jovens de 15 a 25 anos de 22 estados brasileiros, entre 02 e 12 de julho de 1999. (FILGUEIRAS, 1999, p. 24-25). 


\footnotetext{
${ }^{12}$ Deve-se lembrar que, no caso do MST, essa luta se combina com a perspectiva da chamada "educação do campo", aquela que se concretiza, dentre outras coisas, por meio da "construção de escolas nas comunidades rurais e agrovilas dos assentamentos, a todos jovens e adultos do meio rural, como forma de manter os camponeses e as camponesas no meio aonde vivem" (MST, 2010, p. 45).

${ }^{13}$ Caldart (2004, p. 409, grifo da autora) é explícita: “[...] o que costuma ser identificado como sendo a experiência ou a proposta de educação do MST (centrada nos processos de escolarização dos sem-terra) não é mais do que uma das pontas do processo de formação humana que acontece no e através do Movimento.”

${ }^{14}$ Juridicamente, a ENFF é uma associação privada, destinada a atividades de ensino não especificadas para outros tipos de instituições. Nesse sentido, não possui reconhecimento do MEC, maspode estabelecer contratos e convênios com outras entidades e com o poder público.

${ }^{15}$ Mesmo que explicitada diversas vezes por lideranças do movimento, o fato é que não se pode afirmar que essa intenção já tenha sido homogênea no MST.

16 Trata-se da Brigada Apolônio de Carvalho, que "tem a função de administrar do ponto de vista político, pedagógico e funcional” o cotidiano da escola. (GASPARIN, 2009).

${ }^{17}$ Apesar da existência de um Departamento específico para cuidar dos cursos da ENFF, a cada novo curso constitui-se um "coletivo pedagógico" especial, "com participação dos próprios estudantes e professores, para autogestionarem as atividades formativas” (STÉDILE; HILARIO; FUSER, 2013).

${ }^{18}$ A escola não possui reconhecimento formal do Ministério da Educação.

19 A ideia de uma escola de articulação já estava presente no já referido Caderno de formação n. 29, da Campanha de construção da ENFF (MST, 1998).
}

Recebido: maio/2015 Aprovado: jun/2015 